\title{
Does Tourist-Host Social Contact Reduce Perceived Cultural Distance?
}

\begin{abstract}
Tourist-host social contact significantly influences the perceptions of tourists and deserves more attention from scholars in the field of tourism research. However, studies on the relationship between these two constructs are limited. To address this research gap, the present study develops and validates instruments for measuring social contact and perceived cultural distance in the context of tourism, explores the effects of social contact on perceived cultural distance, and provides implications for tourism stakeholders, including governments, tourism operators, and local communities. A survey was conducted among Hong Kong tourists traveling to Mainland China. The study had two significant findings: 1) the quality of contact negatively influences tourists' perceived cultural distance; 2) in terms of the quantity of contact, socialoriented contacts negatively influence perceived cultural distance, whereas service-oriented contacts positively affect perceived cultural distance. Implications were provided to contribute to theoretical and empirical realms, and to guide policy formulation.
\end{abstract}

Keywords: tourist-host contact, perceived cultural distance, quantity of social contact, quality of social contact, policy issues 


\section{INTRODUCTION}

In the tourism academia, social contact and cultural distance are widely believed to play important roles in developing the understanding of intergroup relations, travel experiences, and the attitudes of tourists. Contact between different groups can boost mutual understanding, eliminate bias and stereotypes, and enhance intergroup relations (Allport 1979; Pettigrew 1998; Kawakami et al. 2000; Binder et al. 2009; Kirillova, Lehto, and Cai 2015). Furthermore, such contact may reduce negative emotions — such as anxiety, distrust, and cultural sensitivitytoward outgroups, who are considered socially repulsive (Dovidio et al. 2002; Islam and Hewstone 1993; Stephan and Stephan 1985). Contact between separate groups can also enhance empathy toward outgroups, thereby positively influencing intergroup relations (Baston et al. 1997; Stephan and Finlay 1999). However, social contact may not necessarily lead to a positive change in attitude (Pizam, Jafari, and Milman 1991; Anastasopoulos 1992; Pizam, Uriely, and Reichel 2000; Chen, Lin, and Petrick 2013). Sometimes, intergroup contact may increase tension, hostility, and suspicion. The greater the social contacts are, the more likely that friction and hostility will be triggered (Bochner 1982). Tourist-host social contact—as a unique type of social contact—-deserves more attention from scholars in the field of tourism research considering its remarkable influence on tourists’ perceptions, which is a major determinant in choosing a travel destination. Cultural distance negatively affects tourists’ enthusiasm to travel to a certain region. Cohen (1979) argued that people seek novelty and change when traveling but only to the extent that the novelty and change remain non-threatening. Goeldner and Ritchie (2008) argued that the greater the cultural distance is, the greater the resistance will be. Moreover, Ng, Lee, and Soutar (2007) demonstrated that the greater the perceived cultural similarity of a 
foreign destination with that of the tourists' place of origin, the more likely it is for tourists to visit that destination.

A deeper understanding of the relationship between social contact and cultural distance has the potential to improve relationships among regions, especially those with tension and hostility toward one another. Tourism can transcend governmental boundaries by bringing people closer through personal interaction and the understanding of different cultures (Cho 2007). For these reasons, tourism is considered one of the most important means for promoting peace among the people of the world (Butler and Mao 1996; Anson 1999; Kim and Prideaux 2006; Kim, Prideaux, and Prideaux 2007).

Considering the abundant literature on social contact and cultural distance, some concerns are noted. First, many of the studies largely reflected anecdotal evidence and interpretive evaluations (Allport 1979; Nuñez and Lett 1989; Kirillova et al. 2015). The initial qualitative results provided significant insight, but quantitative assessments on the relationship of the two constructs are also valuable. Moreover, most of the previous studies focused on the diverse effects of social contacts on hosts, and studies investigating the effect of social contact on tourists have not increased much after a few milestone works (e.g., Milman, Reichel, and Pizam 1990; Pizam et al. 1991; Anastasopoulos 1992; Pizam 1996; Pizam et al. 2000). Second, although a large body of literature explores the general relationship between these two constructs (e.g., Pizam and his colleagues), studies that investigate the diverse effects that social contacts have on different aspects of cultural distance are limited. The specific relationship between social contact and cultural distance remains unclear. Additionally, although previous research has applied social contact and cultural distance as measurement instruments, the applicability and fit of the particular instruments used have been criticized (Huang and Hsu 2009; Ng et al. 2007). 
Given the importance of social contact and cultural distance in both academic and empirical realms, this study aims to develop valid measurements for the two constructs and to explore the effects of social contact on cultural distance. Ultimately, the study aims to identify implications for governments, tourism operators, and local communities.

Hong Kong tourists traveling to Mainland China were selected to be the subjects of the current study, considering the notable tourist flow and the tense relationship between the two regions. A questionnaire was designed based on the items developed from in-depth interviews and an expert panel review. After a pilot test, 496 valid samples were collected in Shanghai, Beijing, and Hangzhou from October 2015 to February 2016. Factor analysis and structural equation modeling (SEM) were applied to investigate the relationship between social contact and perceived culture distance.

The remainder of this paper is structured as follows. In the next section, we review studies on cultural distance, social contact, and their relationship. In the third and fourth sections, we introduce the research context and the methodology, respectively. In the fifth section, we present the findings of the study, followed by a discussion and the study's implications. In the final section, we conclude the study and identify its limitations. 


\section{LITERATURE REVIEW}

\section{Cultural distance and its measurement}

Tylor (1924, p1) stated that, “culture is a complex whole which includes knowledge, belief, art, morals, law, custom, and any other capabilities and habits acquired by man as a member of society.” It influences the way humans select, interpret, process, and use information (Triandis 1994). In tourism research, cultural distance refers to the extent to which the culture of the origin region differs from that of the host region (Goeldner and Ritchie 2008). Even if tourists and hosts come from similar cultures and understand each other perfectly, the attitudinal differences between leisure (by tourists) and work (by hosts) may also create social barriers, such as communication style, patterns of behaviors, and standard of service quality, in the interactive activities between the two groups (Nash 1989).

Cohen (1972) argued that the differences between the cultural characteristics of tourists and hosts are the most important variables to compare in tourism studies. As culture holds an extensive range of interpretations, various scholars present different understandings of this concept in their studies. Accordingly, the measurement of culture and cultural difference varies significantly among research topics and research markets.

Recognized as a pioneering framework in this field, Hofstede’s cultural dimensions theory provides a framework consisting of six value dimensions for measuring national culture, including power distance, individualism-collectivism, masculinity-femininity, uncertaintyavoidance, long-term orientation, and indulgence-restraint (Hofstede 1980; Bond 1988; Hofstede, Hofstede, and Minkov 2010). In addition, grid-group cultural theory is another analytical tool of cultural dimensions used in tourism research (Douglas 1982; Caulkins 1999; Li et al. 2015). 
According to this theory, people can be classified into four major social types: individualists, fatalists, hierarchists, and egalitarians (Caulkins, 1999).

With regard to cultural differences from the perspective of tourists, Wei, Crompton, and Reid (1989) argued that attributes, such as accommodation, food, and level of hygiene, involve cultural conflicts that lead to varying perceptions of what constitutes appropriate behavior. Spradley and Philip (1972) stated that cultural differences—specifically differences in food, language, cleanliness, pace of life, recreation, standard of living, transportation, humor, intimacy, privacy, etiquette, and formality—require individuals to adjust. In addition, Reisinger and Turner (1998a, 1998b, 2002a, and 2002b) stated that cultural values, rules of social behavior, perceptions, social (tourist-host) interaction, and satisfaction are essential dimensions that reflect the cultural differences between Western hosts and Asian tourists.

\section{Tourist-host social contact}

Cross-cultural social contact—also called cross-cultural social interaction-refers to the face-to-face contact between people from different cultural backgrounds (Cusher and Brislin 1996; Yu and Lee 2014). Contact theory has been recognized as one of the best approaches to elucidate intergroup relations in psychological and sociological studies. Allport (1979) proposed that intergroup contact and personal interaction can effectively reduce prejudice between group members under certain conditions, such as equal status, common goals, intergroup cooperation, and support from authorities.

Tourist-host social contact is a special form of cross-cultural contact. Tourists typically stay in a destination for short and well-structured periods. Their purposes of travel set them apart from other inter-cultural contacts, such as those of immigrants and temporary sojourners (Pearce 1982). With the different tourists' types and travel modes, their degree of contact with the hosts 
varies (Woosnam and Aleshinloye 2012; Rasmi et al. 2014; Kirillova et al. 2015; Luo, Brown, and Huang 2015).

As a fundamental work in the research on tourist-host social contact, Cohen (1972) developed a fourfold tourist typology. According to the degree of familiarity and novelty in travel, tourists can be categorized into four types: organized mass tourist, individual mass tourist, the explorer, and the drifter. Further categorization labels the first two tourist types as "institutionalized tourist roles" and the other two as "non-institutionalized tourist roles." Institutionalized tourists are socially separated in terms of their destination, whereas noninstitutionalized tourists meet a wide variety of people and experience deep contact with the local community. Cohen's study pioneers and sheds light on the relational exploration between social contact and tourists' attitude toward destinations.

\section{Measurement of social contact}

Cohen (1972, p177) emphasized that, "the degree to which and the way they [tourists and hosts] affect each other depends largely on the extent and variety of social contacts the tourist has during his trip." Some studies have thus far explored the "extent" and "variety" of touristhost social contact. Rothman (1978), Mo, Howard, and Havitz (1993), and Reisinger and Turner (2002a, b) applied activities of social contact as the only measurement of social contact. Woosnam and Aleshinloye (2012) adopted contact frequency as a measurement of tourist-host interaction.

Other studies have considered multiple dimensions to measure social contact. In evaluating residents’ attitude toward tourism development, Akis, Peristianis, and Warner (1996) considered the quality and frequency of tourist-host social contact. Islam and Hewstone (1993) tested how qualitative, quantitative, and intergroup contacts were related to various dependent 
variables. Berscheid, Snyder, and Omoto (1989) considered the frequency, activity, and strength of social contact in assessing the closeness of interpersonal relationships. Building on the results obtained by Berscheid et al. (1989) and Islam and Hewstone (1993), Huang and Hsu (2009) examined the activity, frequency, influence, valence, intensity, power, and symmetry of customer-to-customer interaction on cruises.

The functions of social contact have been addressed in socio-psychological research along with the application of Allport's (1979) contact theory and other related studies (Bochner 1982; Cusher and Brislin 1996; Yu and Lee 2014). As a unique type of social contact, touristhost social contact warrants further exploration. However, in most previous research, which applied social contact to assess tourists' impact on host communities (Islam and Hewstone 1993; Huang and Hsu 2009; Luo et al. 2015), measurement items were adopted from other disciplines without validation in the field of tourism. The overlook on the exploration of the various dimensions of social contact per se led to an inconsistency in the application of social contact. To address these shortcomings, this study aims to establish a system of tourist-host social contact with a comprehensive understanding of its diverse dimensions.

Cohen (1972) argued that the "extent" and "variety” of social contact between tourists and hosts can determine the degree to which and the way the two groups affect each other. Based on the literature, the "extent" of social contact can be explained by the quality of social contact, and the "variety" of social contact can be represented by the quantity of social contact. Therefore, the current study adopts both the qualitative and quantitative aspects to measure social contact.

Particularly, the measurement of the quality of contact can be adopted from previous research (Wish 1976; Islam and Hewstone 1993; Akis et al. 1996; Huang and Hsu 2009). Considering the measurement of the quantity of contact, activities and frequency were applied 
(Huang and Hsu 2009). In preceding studies, activities and frequency were measured separately. Activities were represented by the number of interactions that tourists have during their trips, and the total number for all of the items were accumulated to represent the activities as a whole. Frequency was measured by the duration of contact, for instance, the average amount of time spent interacting with others in the morning, afternoon, and evening (Huang and Hsu 2009). The concerns for such measurement are twofold. First, results generated from this method cannot provide a categorization of the contact activities, thus failing to identify the diverse influences of different contact activities on other attributes, such as travel experience (Huang and Hsu 2009) and intercultural sensitivity (Kirillova et al. 2015). Second, the frequency measured in previous studies was also a collective concept, which did not specify the particular time allocated to each of the activities. As a result, the individual performance of each item in terms of the quantity of social contact is overlooked. To address this measurement gap, the current study develops a measurement that simultaneously considers the activity and its frequency. Each contact activity is rated by the degree of frequency a tourist had with hosts, from a range of "never" to "very frequently.”

\section{Relationship between social contact and perceived cultural distance}

Research findings on the effects of tourist-host social contact on tourists' perceptions of cultural distance are conflicting. MacCannell (1976) argued that all tourist attractions are cultural experiences that include representations of cultural models as well as influences based on those models. A medium, such as face-to-face interaction, is an agency that connects a cultural model and its influences. Researchers (Amir 1969; Allport 1979; Pizam 1996) conducted several experiments and studies and found that tourism may not necessarily promote peace in most cases. Sometimes, tourism may even lead to negative attitudinal changes (Milman et al. 1990; Pizam et 
al. 1991; Anastasopoulos 1992; Pizam et al. 2000). As indicated in Pizam’s (1996) work, to achieve positive changes in ethnic relations, certain conditions must be present in contact situations, such as equal-status contact, intergroup cooperation, and authority (Amir 1969, 1976; Cook 1962).

Anthropologists define acculturation as the changes that occur when different cultural groups come into intensive contact (Segall 1979; Berry 1997). Acculturation is the process of adjusting to a new culture and the degree of involvement with the new environment (Rasmi et al. 2014; Tsai, Chentsova-Dutton, and Wong 2002). In this process, when two cultures come into contact regardless of duration, each becomes, to a certain extent, similar to the other through borrowing (Nuñez and Lett 1989). In studies on acculturation, contact between cultures is considered to be the most powerful force that induces cultural changes (Segall 1979). Tourism is a two-way acculturation process: the host culture influences visitors and is also influenced by them.

In conclusion, the evidence that supports the causal relationship between social contact and perceived cultural distance is twofold. First, social contact may generate positive intergroup relations, thereby reducing the tension and prejudices among groups if the contact is under certain conditions. Perceived cultural distance, as one type of perception, is also influenced by individuals’ affective judgment. The more contact that tourists have with locals, the more positive is the attitude they hold toward their hosts, and the more similarly they perceive themselves with the locals. Second, the acculturation process shows that contact is the main force that influences individuals' cultural value. The more that tourists interact with the destination hosts, the more psychological and perceptual changes they will have, the more they will immerse 
themselves in the local culture, and the more they will perceive themselves to be similar to the locals. Thus, the following hypotheses were assumed:

H1: The quantity of tourist-host social contact is negatively associated with perceived cultural distance.

H2: The quality of tourist-host social contact is negatively associated with perceived cultural distance. 


\section{RESEARCH CONTEXT}

Hong Kong tourists traveling to Mainland China were selected to be the subjects of the current study. Political and historical relationships between Hong Kong and Mainland China has gained increasing attention worldwide. Hong Kong’s long-time colonization by the United Kingdom and its separation from Mainland China make Hong Kong and Mainland China ethnically the same but ideologically different regions. Conflicts, prejudices, hostility, and tension between the two groups (predominantly expressed by Hong Kong residents) have been reported since the handover of Hong Kong, and such negative sentiments have become even more severe in recent years. Growing inter-regional communication and economic exchange have led to problems between Hong Kong and Mainland China, including issues with the personal etiquette of tourists (Ko 2012; Apple Daily 2014), perceived discrimination (Ming Pao 2013), and in terms of economic exchange, the growing prevalence of smugglers (Chow 2012).

Despite this tension in their relationship, Mainland China has long been the most preferred outbound travel destination for Hong Kong residents. According to the Hong Kong Census and Statistics Department (2015), the proportion of trips to Mainland China in overall outbound trips for Hong Kong residents was 85\% in 2014. As for Mainland China's inbound tourism, Hong Kong is its largest inbound tourism source market. Visitors from Hong Kong represented 60\% of the total inbound visitors in 2014 (China National Tourism Administration 2015). Considering such a remarkable tourist flow and the tense relationship, social contact and perceived cultural distance can provide important information for the Chinese and Hong Kong governments, which are often faced with the task of reducing tensions and conflicts between the two regions. 


\section{METHODOLOGY}

\section{Instrument development}

The mixed-methods approach was adopted to develop both valid and reliable measurement instruments. In this study, three constructs were measured, namely, cultural distance, quantity of contact, and quality of contact. The measurement of cultural distance was represented by perceived cultural distance, as recommended in the literature, and the measurement instrument of quantity of contact, activities, and frequency were adopted.

In the absence of substantial measurements regarding perceived cultural distance and quantity of contact, we adopted semi-structured, in-depth interviews to generate rich information. The target population for the current study is permanent residents of Hong Kong who have traveled to Mainland China for leisure purposes in the past two years. Three approaches were adopted in the interviews. First, to get interviewees warmed up to the topic, they were asked about their travel experiences to Mainland China. Second, after the warm up, interviewees were requested to evoke any memories of perceived cultural distance they may have encountered during their travel. Third, informants were required to share about their interactions with their hosts. The interviewers stopped inviting new informants when reaching information saturation. As a result, 23 qualified informants were interviewed. Each session lasted for about 26 to 88 minutes. All of the interviews were recorded and transcribed. Interviews were conducted in the interviewees’ mother tongues and then translated into English. To ensure the accuracy and credibility of the translation, two professional language editors (skilled in Cantonese and English) were tasked to be language consultants during the translation. Textual data from the transcripts were interpreted and thematically analyzed. NVivo 10 software was applied to technically code and organize the transcripts. Consequently, 19 items of perceived cultural distance and 16 items 
of contact activities were revealed. In addition, 16 items of the quality of social contact were consolidated from the literature (Wish 1976; Islam and Hewstone 1993; Akis et al. 1996; Huang and Hsu 2009).

An expert panel review was conducted to assess the content validity in each construct of the newly developed items and of those adopted from the literature. Six research faculty members and four PhD candidates with expertise in cross-cultural studies were invited to evaluate the existing items by using a three-point Likert-type scale, ranging from "inappropriate” to “appropriate.” After the panel review, 19 items of cultural distance, 14 items of the quantity of contact, and 16 items of the quality of contact were retained in the conceptual model (Figure 1).

\section{Insert Figure 1 Here}

\section{Questionnaire design}

A questionnaire was developed according to the results from both the interviews and the panel review. The questionnaire comprised two sets of questions. The first set was intended to obtain respondents’ perceptions of perceived cultural distance, quantity of social contact, and quality of social contact with the hosts. Perceived cultural distance and quality of social contact were evaluated using a five-point Likert-type scale. The quantity of social contact was measured by the frequency of participation in a certain activity, with 1 representing “never” and 5 for “very frequently.” The second set was intended to obtain the respondents’ demographic information.

A pilot test was conducted prior to the main survey. A total of 69 students who enrolled in a course in a Hong Kong university and 254 friends and relatives of the students finished the survey of which 283 responses were valid. To ensure the cross validity, exploratory factor 
analysis (EFA) was applied to the samples of the pilot test, and confirmatory factor analysis (CFA) to the main survey samples. After the EFA, ten items were retained for perceived cultural distance, and three factors emerged, namely, cultural retention (four items), behavioral characteristics (four items), and social characteristics (two items). Similarly, social-oriented contact (seven items) and service-oriented contact (seven items) were identified as two factors of the quantity of contact. The quality of contact (seven items) was represented by a single factor. Based on the information collected from the pilot test, 18 items were deleted due to low loading or cross loading issues. The wording of some items was modified according to respondents' feedback. For example, "People in Mainland China and Hong Kong are different in terms of restrictions in freedom" was found too broad for the respondents to understand. Therefore, some examples (e.g., blocking foreign websites, forbidding protests) were supplemented to facilitate understanding.

\section{Sampling and data collection}

To represent the majority of Hong Kong tourists to Mainland China, the current study adopted quota sampling as the sampling method. To ensure that certain subgroups are included in the sample, quota sampling is applied (Hemmington 1999). This sampling method can be applied in either probability or non-probability samplings. In the current study, once the number of sample units has been calculated for each subgroup, the selection process is conducted by convenience (Jennings 2001). The application of quota sampling can ensure the presence of certain characteristics of the population from different sample groups. Quota sampling may bear some shortcomings as well, particularly in terms of sampling error and representation issues, and the ignorance of other characteristics in the population (Dudovisky 2013). 
The five-year inbound visitors statistics between 2009 and 2013 (China National Tourism Administration, 2014) reveals that Shanghai, Beijing, and Hangzhou were the top three destination cities for Hong Kong overnight travelers. Guangdong provinces and the city of Quanzhou (in the Fujian province) were excluded from the current study to avoid the potential influences of cultural similarity as well as the considerable number of immigrants to Hong Kong in the current model. In terms of the total sample size, Byrne (2010) stated that, for Analysis of Moment Structures (AMOS), sample sizes should exceed 10 times of the number of estimated variables to generate reliable results. Considering that the total number of items was 31 , the sample size aimed for this survey was 500. According to the relative market share (Shanghai: Beijing: Hangzhou = 5: 3: 2), the quota set for the three destinations were 250, 150, and 100, respectively.

On-site data collection was conducted in the airport departure hall of each of the three selected cities from October 2015 to February 2016. This period included both low travel seasons (late October, November, and early December) and peak travel seasons (Christmas, New Year, and Chinese New Year) for Hong Kong residents. In this study, the duration can ensure the reasonable combination of individual tourists, package tourists, and business travelers. The first author and five student helpers were working near the check-in counters of Cathay Pacific, Dragonair, and Air China, which are airlines that provide flight service from different destinations to Hong Kong. After checking in for their flights, travelers were approached by the data collection team. Considering the research topic, respondents were told to answer anonymously and individually to avoid any social desirability issue. They were also instructed to answer according to their perceptions as there were no right or wrong answers. To stimulate respondents to participate, incentives were provided afterwards. The questionnaires were 
collected and carefully checked on site to ensure their completion. As a result, 257 responses were collected from Shanghai, 174 from Beijing, and 91 from Hangzhou. The slight deficiency of the Hangzhou sample was brought about by the relatively low travel season (late October and November) during the data collection period. In total, 522 questionnaires were completed, of which 496 were valid.

\section{Data analysis}

On collection, all responses were categorized, scaled, and entered into the Statistical Package for Social Sciences program for processing. Data screening was conducted to detect outliers and any serious violations of assumptions. Descriptive analysis (e.g., frequency and means) was performed to profile the respondents' characteristics and to compose the descriptive information of all attributes. CFA was performed on the main survey data set via the AMOS to further confirm the structure and dimensionality of the factors. Composite reliability was performed to examine the internal reliability of each factor. The validity of these factors was tested using convergent validity, discriminant validity, and overall fit indices. After a test of the measurement model, SEM was performed to examine the relationships based on the hypotheses proposed. The magnitude of each relationship was represented by the path coefficient. The data analysis process is discussed in detail in the following section. 


\section{FINDINGS}

Table 1 shows a demographic profile of the main survey respondents. A total of 496 valid responses were collected. Male respondents (54.5\%) outnumbered female respondents (45.5\%). On the age of the respondents, 37\% were between 45 and 64 years old; $26.7 \%$ were between 35 and 44 years old; and 22.6\% were between 25 and 34 years old. Approximately two thirds of the respondents held bachelor degrees. On employment, 80\% of the respondents held jobs; among the $80 \%, 37.3 \%$ of the employed respondents categorized themselves as managers and administrators, and $29.6 \%$ categorized themselves as professionals. According to the Hong Kong Census and Statistics Department (2016), more than 60\% of the respondents held a higher household monthly income than the median (25,000 HKD). Therefore, the majority of the respondents were from the middle or upper middle class in Hong Kong, constituting the main force of outbound travel. One third of the respondents were single, and half of them were married and had child(ren). On the survey’s generalizability, the demographic profile of respondents in the current study was compared with the socio-economic characteristics of Hong Kong travelers to Mainland China reported by the Hong Kong Census and Statistics Department (2015). The report revealed that 55\% of the travelers were male; 26\% were between 50 and 59 years old, 18\% were between 40 and 49 years old; and 12.6\% were between 30 and 39 years old. The comparison showed a consistency between the survey sample and the population in accordance with the gender and age distributions.

\section{Insert Table 1 Here}




\section{Measurement model}

CFA was performed to further validate the measurement developed by EFA. Missing data were eliminated through listwise deletion before conducting CFA. An assessment of normality and outliers was conducted according to Mahalanobis D-squared values.

Average variance extracted (AVE) was calculated for each construct to estimate the convergent validity, and the results were between 0.487 and 0.636 . Therefore, convergent validity was established (Song, Xing, and Chathoth 2015; Ye, Zhang, and Yuen 2013). All of the retained items and their corresponding factor loadings are shown in Table 2. In this study, each of the squared correlations between any two constructs was smaller than the corresponding AVE (Table 3), confirming the discriminant validity of the measurement scale (Hair et al. 2010).

The composite reliability of the six factors ranged from 0.740 to 0.890 , which showed the acceptable construct reliability of the model (Bagozzi and Kimmel 1995). The overall model fit was also investigated using various indices. The chi-square $\left(\mathrm{X}^{2}\right)$ test assesses the closeness of fit between the model and the data. The $\mathrm{X}^{2}$ was 480.327, and degree of freedom (df) was 255 . The $\mathrm{X}^{2} / \mathrm{df}$ equaled 1.884 , indicating a good model fit. The RMSEA value was 0.042 , and CFI and TLI values were 0.962 and 0.955 , respectively, which further supported the favorable fit of the model (Hair et al. 2010).

\section{Insert Tables 2 and 3 Here}

\section{Structural model}

The proposed structural model based on the hypotheses was assessed by the path analysis, and the indices obtained suggested a well-fitted model. Specifically, the $\mathrm{X}^{2}$ was 801.181 , df was 
258, and the $\mathrm{X}^{2} / \mathrm{df}$ equaled 3.105. CFI and TLI were 0.907 and 0.892, respectively, which indicated a well-fitted model. Figure 2 shows the estimated path coefficients in SEM. As indicated in the quantity of contact, social-oriented activities negatively affect the perceived cultural distance dimension $(\beta=-0.160, p=0.049$ for cultural retention; $\beta=-0.210, p=0.017$ for behavioral characteristics; $\beta=-0.221, p=0.016$ for social characteristics). By contrast, serviceoriented activities positively affect the perceived cultural distance dimensions ( $\beta=0.329, \mathrm{p}<0.001$ for cultural retention; $\beta=0.371, p<0.001$ for behavioral characteristics; $\beta=0.281, p=0.005$ for social characteristics). Lastly, the quality of contact negatively affects perceived cultural distance in terms of cultural retention, behavioral characteristics, and social characteristics $(\beta=-0.116$, $\mathrm{p}=0.030 ; \beta=-0.247, \mathrm{p}<0.001 ; \beta=-0.208, \mathrm{p}=0.002$, respectively).

\section{Insert Figure 2 Here}




\section{DISCUSSION AND IMPLICATIONS}

Tourism has long been regarded as a way of facilitating intergroup understanding. The present study extended and confirmed Allport's (1979) contact theory regarding the contact effect in a tourism context.

Adopting both qualitative and quantitative approaches, measurements of perceived cultural distance and quantity of social contact were developed and validated. Three factors of perceived cultural distance were identified, namely, cultural retention, behavioral characteristics, and social characteristics. The findings showed consistency with previous literature, which argued that tourists’ perceived cultural distance is related to various factors, such as food, privacy, cleanliness, rules of social behaviors, communication, and cultural values (Wei et al. 1989; Spradley and Philip 1972; Reisinger and Turner 1998a, 1998b, 2002a, and 2002b). These factors are well recognized as the core of conflicts and tension between Mainland Chinese and Hong Kong residents (Ko 2012; Apple Daily 2014). As reported by Ye et al. (2013), perceived cultural distance led to intergroup discrimination and negatively affected the intergroup relationship.

Based on a rigorous research method, the current study supported the argument that both quantity and quality aspects of social contact are associated with tourists’ perceived cultural distance. Specifically, the quality of contact negatively affects perceived cultural distance. As one of the most notable findings in this study, two kinds of contact quantity were found to have opposite effects on the perceived cultural distance. Social-oriented contact has a significantly negative effect on perceived cultural distance. Service-oriented contact, however, positively affects perceived cultural distance. 
Consistent with previous literature, the current study showed that the quality of contact plays a salient role in affecting individuals’ perceptions (Binder et al. 2009; Huang and Hsu 2009; Kirillova et al. 2015). According to Allport's (1979) contact theory, positive contact may occur when certain criteria, such as equal status, cooperation, personal interaction, are met. The quality of contact in the present study essentially indicates optimal conditions for positive contact as mentioned in contact theory (i.e., harmonious versus clashing, equal versus unequal, friendly versus hostile, cooperative versus competitive, and intense versus superficial). For this reason, tourists who have more positive and in-depth contact with the mainland locals would perceive less cultural distance during their travel. The pervasive effect of the quality of contact may also be due to its nature. As interpreted by Huang and Hsu (2009), the quality of contact is an individual's subjective evaluation of their overall contact, which is heavily determined by an individual's affect toward the contact points. Alternatively, the feelings may overshadow the objective assessment on perceived cultural distance (Berscheid et al. 1989). An equal, cooperative, intense, and friendly interaction with hosts may create a positive and favorable relationship between tourists and hosts and thereby lead to a close feeling and perceived similarity between two groups.

Interestingly, the present study reveals that the quantity of contact can also play a role in influencing the outcome of social contact. As argued in previous literature, the quality of contact plays a dominant role as compared with the quantity of contact (Binder et al. 2009; Huang and Hsu 2009; Islam and Hewstone 1993; Schwartz and Simmons 2001). The quantity of contact has been regarded as an insignificant element in the study of social contact (Nash 1989). The significant effect of the quantity of social contact is the result of the new measure of social contact that has been introduced in the current study. As mentioned in the Instrument 
development section, various activities of social contact were treated equally to predict the outcome in previous studies. In reality, however, asking for information and visiting hosts’ homes may not provide equal opportunities for tourists to understand locals and their life. This circumstance might be the main reason why the quantity of social contact in previous studies was claimed to have no significant effect on individuals' perceptions. The current study considers an activity and its corresponding frequency simultaneously to provide a precise approach for analyzing the effect of each activity on perceived cultural distance. Items were also categorized by EFA, and two sub-constructs were generated accordingly, namely, a social-oriented aspect and a service-oriented aspect.

Social-oriented contacts are those contacts with social purposes, such as making friends, visiting locals' homes, exploring the locals' daily life, and traveling together. Due to the nature of social purposes, these activities are interactive and intense, as they require people to have more commitment to one another. As revealed in this study, social-oriented contacts can reduce tourists’ perceived cultural distance. Ye et al. (2013) found that perceived cultural distance leads to intergroup discrimination and negatively affects intergroup relationships. For this reason, social-oriented activities should be encouraged between tourists and hosts to nurture mutual understanding and communication between the two groups.

Comparatively, service-oriented social contacts have a positive relationship with perceived cultural distance. Such kinds of contact include interaction with service personnel during service encounters, such as in dining, shopping, transportation, accommodation, and touring. The more service-oriented contacts a tourist has with the hosts, the more cultural distance he or she will perceive between the home culture and the destination culture. Serviceoriented social contacts may happen more frequently between tourists and hosts compared with 
social-oriented contacts. Service-oriented contacts require a short communication period and limited interaction. Therefore, these contacts tend to be superficial and standardized. According to contact theory (Allport 1979, Pizam et al. 2000; Yu and Lee 2014; Luo et al. 2015), contacts can positively influence individuals' perceptions of other groups if such contacts involve intensive, personal, and informal interactions. However, because of their shallow nature, serviceoriented contacts are likely to be ineffective as a way for tourists to achieve the aforementioned conditions. Each time a tourist contacts a host in a service-oriented situation, the tourist may experience culture shock induced by the cultural distance between the two parties. Extensive and repeated experiences of a shallow nature collectively reinforce the tourist's sense of difference between the two parties, and these experiences increase the perceived cultural distance.

\section{Practical implications}

This study also provides implications for governments, tourism operators, and local communities. It is viable that reception parties of tourism must be the ones to consider our findings and take actions, as tourists cannot be expected to make the adaptations necessary for involving themselves in the essential life of the host society. As Nash (1989) and Pizam et al. (2000) recommended, considering the gap between tourist-host groups, certain intergroup specialists, such as diplomats, community relations experts, and relevant organizations, should be mobilized to make improvements if a favorable tourist-host relationship is to continue.

First, tourist-host social contact is relevant to tourists' perceptions of cultural distance. The strong impact of tourist-host social contact on perceived cultural distance suggests that cultivating proper contacts (social-oriented contacts) between two groups may enhance intergroup mutual understanding and thus cultivate a favorable relationship. A survey conducted by Hong Kong University showed that $77.4 \%$ of Hong Kong residents stated that they were 
Hong Kong citizens, and only 59\% agreed that they were citizens of the People’s Republic of China (HKU Public Opinion Programme 2012). These results show that a considerable portion of Hong Kong residents would like to be distinguished from residents of Mainland China. With this jeopardizing situation, government officials from both sides should consider promoting more personal and favorable contacts between Hong Kong tourists and mainland hosts to 1) engender a sense of cultural similarity and national identity, and 2) to reduce tension, prejudices, and hostility.

The empirical outputs of this study can also be used to guide policymakers and stakeholders concerned with managing the problems arising from tourist-host interaction. Applying this study's outputs will first require careful identification by the various stakeholders and regulatory authorities involved. Furthermore, the participation of community representatives is a key component. In countries, such as Indonesia, tourism-awareness campaigns have been used for many years to inform residents of the benefits of tourism and the behavioral characteristics of tourists. Often introduced as a school subject, tourism awareness can help local people gain awareness of and become tolerant of behavioral differences in their tourist visitors. However, the tourist-host interface has two dimensions, and tourists should be sensitized to the social-behavioral expectations of their hosts.

Second, as reflected in our findings, social-oriented contacts with locals would lead to less perceived cultural distance, but service-oriented contacts would increase the perceived cultural distance felt by Hong Kong tourists. Tourism operators and product planners could design some itineraries that involve socially intense activities with locals, such as visits by tourists to local communities (non-tourism areas). Another opportunity for social-oriented contact could be the provision of resident volunteers to tourist information centers. The 
engagement in positive and favorable intergroup relationships from such types of contact may foster favorable travel experiences and high levels of service satisfaction through the influence of positive customer perceptions. Another approach to encouraging social-oriented contacts is the penetration of the niche tourism market, which offers unique kinds of contacts, such as bed and breakfasts (B\&Bs), farm tourism, and voluntourism. Lastly, local residents can also contribute to the local tourism industry and help in the development of a hospitable destination image for their region by proactively interacting with tourists and by going out of their way to engage with them in a positive and welcoming manner. 


\section{CONCLUSION AND LIMITATIONS}

The present study tested the relationship between social contact and perceived cultural distance in the tourist-host context. The emerging awareness of the effects of social contact on tourists has been emphasized. Our findings support the argument that both the quantity and quality of social contact are associated with tourists’ perceived cultural distance. The quality of contact was reported to have a negative effect on perceived cultural distance. Our findings also revealed, however, that the quantity of contact influenced tourists' perceived cultural distance in two different ways: social-oriented contacts negatively affect perceived cultural distance, but service-oriented contacts positively affect perceived cultural distance. The findings provide insight into the ways in which different types of contact affect individuals' perceptions through tourism activities. Moreover, a new measurement technique for tourist-host social contact was developed, which could facilitate further empirical research to investigate its antecedents (such as facilitators, constraints, and purposes of tourist-host social contact) and consequences (such as the effects of contacts). Practical contributions were also discussed to provide insight for governments, tourism operators, and communities.

However, this study brings with it the following limitations and considerations. First, convenience sampling was applied within each quota. The limitations related to the convenience sampling, such as the data representation issue, should be noted. Second, this research only includes top three destination cities as the quota base. Future research can consider expanding the sample scope to cover more destination cities in Mainland China. Third, cultural distance plays a significant role in determining the tourist-host relationship. As described by Sutton (1967), social contact outcomes can be classified into three types based on the distance between two original cultures: 1) the same (or similar); 2) different, with the differences being small and 
supplementary; and 3) different, with the differences being large and difficult to tolerate by either side. In the current study, culture in the two regions are different, but the differences are small and supplementary. For this reason, the perceived cultural distance can be lessened by certain social contacts. This study does not, however, confirm the relationships in the first and third types in Sutton's (1967) work, which refer to the relationship between two culturally similar groups and the relationship between groups with largely different cultures. The relationship between social contact and perceived cultural distance in the other two settings deserves further investigation to contribute a comparable understanding to the body of knowledge.

In addition, this study can be replicated in other countries to further examine the validity of the methodological approach. Continuing exploration of tourist-host contact using quantitative techniques would provide further insight into this research area. The concept of social contact may also be tested in both tourist and host groups simultaneously to obtain its effects from both perspectives. 


\section{REFERENCES}

Akis, Sevgin, Nicos Peristianis, and Jonathan Warner. 1996. "Residents' attitudes to tourism development: the case of Cyprus." Tourism Management 17 (7): 481-494.

Allport, Gordon Willard. 1979. The Nature of Prejudice: Reading, MA: Addison-Wesley Pub.

Amir, Yehuda. 1969. “Contact Hypothesis in Ethnic Relations.” Psychological Bulletin, 71:31942.

Amir, Yehuda. 1976. "The role of intergroup contact in change of prejudice and ethnic relations.” In Towards the Elimination of Racism, edited by P. A. Katz. New York: Pergamon.

Anastasopoulos, Petros G. 1992. "Tourism and attitude change: Greek tourists visiting Turkey." Annals of Tourism Research 19(4): 629-642.

Anson, Caroline. 1999. "Planning for peace: The role of tourism in the aftermath of violence”. Journal of Travel Research 38 (1): 57-61.

Apple Daily. 2014, April 25. The Furore Brought by A Kid's Feces. Retrieved August 28, 2014 from http://hk.apple.nextmedia.com/news/art/20140425/18700311

Bagozzi, Richard P., and Susan K. Kimmel. 1995. "A comparison of leading theories for the prediction of goal - directed behaviours." British Journal of Social Psychology 34 (4): 437-461.

Batson, C. Daniel, Marina P. Polycarpou, Eddie Harmon-Jones, Heidi J. Imhoff, Erin C. Mitchener, Lori L. Bednar, Tricia R. Klein, and Lori Highberger. 1997. "Empathy and attitudes: Can feeling for a member of a stigmatized group improve feelings toward the group?." Journal of Personality and Social Psychology 72 (1): 105-118.

Berry, John W. 1997. "Immigration, acculturation, and adaptation." Applied Psychology 46(1): 5-34. 
Berscheid, Ellen, Mark Snyder, and Allen M. Omoto. 1989. "The Relationship Closeness Inventory: Assessing the closeness of interpersonal relationships." Journal of Personality and Social Psychology 57(5): 792-807.

Binder, Jens, Hanna Zagefka, Rupert Brown, Friedrich Funke, Thomas Kessler, Amelie Mummendey, Annemie Maquil, Stephanie Demoulin, and Jacques-Philippe Leyens. 2009. "Does contact reduce prejudice or does prejudice reduce contact? A longitudinal test of the contact hypothesis among majority and minority groups in three European countries." Journal of Personality and Social Psychology 96(4): 843-856.

Bochner, Stephen. 1982. “The social psychology of cross-cultural relations”. In Stephen Bochner Cultures in Contact: Studies in Cross-Cultural Interaction (5-29). Oxford, UK: Pergamon Press Ltd.

Bond, Michael H. 1988. "Finding universal dimensions of individual variation in multicultural studies of values: The Rokeach and Chinese value surveys." Journal of Personality and Social Psychology 55(6): 1009-1015.

Butler, Richard W., and Baodi Mao. 1996. "Conceptual and theoretical implications of tourism between partitioned states." Asia Pacific Journal of Tourism Research 1(1): 25-34.

Byrne, Barbara MB. M. 2010. "Structural Equation Modeling with AMOS: Basic Concepts, Applications, and Programming." (2nd Ed.). New York: Taylor \& Francis Group.

Campbell, Donald T. 1967. "Stereotypes and the perception of group differences." American Psychologist 22(10): 817-829.

Caulkins, D. Douglas. 1999. "Is Mary Douglas's grid/group analysis useful for cross-cultural research?." Cross-Cultural Research 33(1): 108-128.

Chen, Chun-Chu, Yueh-Hsiu Lin, and James F. Petrick. 2012 "Social biases of destination perceptions." Journal of Travel Research 52(2): 240-252.

China National Tourism Administration. 2014. The Yearbook of China Tourism Statistics 2014. Beijing: China Travel and Tourism Press. 
China National Tourism Administration. 2015. The Yearbook of China Tourism Statistics 2014. Beijing: China Travel and Tourism Press.

Cho, Minho. 2007. "A re-examination of tourism and peace: The case of the Mt. Gumgang tourism development on the Korean Peninsula." Tourism Management 28(2): 556-569.

Choo, Hyungsuk, and James F. Petrick. 2014. "Social interactions and intentions to revisit for agritourism service encounters." Tourism Management 40: 372-381.

Chow, V. 2012, February 1. “Anger at Mainland visitors escalates with 'locust' ad”. South China Morning Post, City 1.

Cohen, Erik. 1972. “Toward a sociology of international tourism”. Social Research, 39(1): 164182.

Cohen, Erik. 1979. “A phenomenology of tourist experiences”. Sociology, 13(2): 170-201.

Cook, Stuart W. 1962. “The systemic analysis of socially significant events: A strategy for social research.” Journal of Social Issues, 18 (1):66-84.

Cushner, Kenneth, and Richard W. Brislin. 1996. Intercultural Interactions: A Practical Guide. Thousand Oaks, CA: Sage.

Douglas, Mary. 1982. In the Active Voice. Routledge: London.

Dovidio, John F., Samuel E. Gaertner, Kerry Kawakami, and Gordon Hodson. 2002. "Why can't we just get along? Interpersonal biases and interracial distrust." Cultural Diversity and Ethnic Minority Psychology 8(2): 88.

Dudovisky, John. 2013. An Ultimate Guide to Writing a Dissertation in Business Studies: A Step-by Step Assistance.

Goeldner, Charles R., and JR Brent Ritchie. 2008. Tourism: Principles, Practices, Philosophies. John Wiley \& Sons, Inc.. Retrieved 15 October 2013, from http://www.myilibrary.com?ID=176679 
Hair, Joseph F., William C. Black, Barry J. Babin and Rolph E. Anderson. 2010. Multivariate Data Analysis (7th Ed.), Upper Saddle River, New Jersey: Pearson Education, Inc.

Hemmington, Nigel. 1999. "Sampling”. In B. Brotherton The Handbook of Contemporary Hospitality Management Research (255). Chichester, UK: John Wiley and Sons Ltd.

HKU Public Opinion Programme 2012. HKU POP Releases Latest Survey on Hong Kong People's Ethnic Identity. Retrieved November 11, 2013 from The University of Hong Kong, Public Opinion Programme Web site: http://hkupop.hku.hk/english/release/release987.html

Hofstede, Geert, Gert Jan Hofstede, and Michael Minkov. 2010. Cultures and Organizations: Software of the Mind. ( $3^{\text {rd }}$ Edition) U.S.: McGraw-Hill.

Hofstede, Geert. 1980. Culture's Consequences: International Differences in Work-Related Values. Beverly Hills, CA: Sage.

Hong Kong Census and Statistics Department. 2015. Socio-Economic Characteristics and Consumption Expenditure of Hong Kong Residents Making Personal Travel to the Mainland of China, 2014. Retrieved January 1, 2016 from Hong Kong Special Administrative Region, Web site: http://www.statistics.gov.hk/pub/B71511FB2015XXXXB0100.pdf

Hong Kong Census and Statistics Department. 2016. Wage and Labor Earnings. Retrieved Nov 20, 2016 from Hong Kong Special Administrative Region, Web site: http://www.censtatd.gov.hk/hkstat/sub/sp210.jsp?productCode=D5250017

Huang, Jue, and Cathy HC Hsu. 2009. "The impact of customer-to-customer interaction on cruise experience and vacation satisfaction." Journal of Travel Research, 49(1): 79-92.

Islam, Mir Rabiul, and Miles Hewstone. 1993. "Dimensions of contact as predictors of intergroup anxiety, perceived out-group variability, and out-group attitude: An integrative model." Personality and Social Psychology Bulletin 19(6): 700-710.

Jennings, Gayle. 2001. Tourism Research. John Wiley and sons Australia, Ltd. 
Kawakami, Kerry, John F. Dovidio, Jasper Moll, Sander Hermsen, and Abby Russin. 2000. "Just say no (to stereotyping): effects of training in the negation of stereotypic associations on stereotype activation." Journal of Personality and Social Psychology 78(5): 871-888.

Kim, Samuel Seongseop, and Bruce Prideaux. 2006. "An investigation of the relationship between South Korean domestic public opinion, tourism development in North Korea and a role for tourism in promoting peace on the Korean peninsula." Tourism Management 27(1): 124-137.

Kim, Samuel Seongseop, Bruce Prideaux, and Jillian Prideaux. 2007. "Using tourism to promote peace on the Korean Peninsula." Annals of Tourism Research 34(2): 291-309.

Kirillova, Ksenia, Xinran Lehto, and Liping Cai. 2015. "Volunteer Tourism and Intercultural Sensitivity: The Role of Interaction with Host Communities." Journal of Travel \& Tourism Marketing 32(4): 382-400.

Ko, V. 2012. Trouble Down South: Why Hong Kong and Mainland Chinese Aren't Getting Along. Retrieved November 11, 2013 from http://world.time.com/2012/01/24/troubledown-south-why-hong-kong-and-mainland-chinese-arent-getting-along/

Li, Mimi, Hanqin Zhang, Honggen Xiao, and Yong Chen. 2015. "A Grid-group Analysis of Tourism Motivation." International Journal of Tourism Research 17(1): 35-44.

Luo, Xianrong, Graham Brown, and Songshan Sam Huang. 2015. "Host perceptions of backpackers: Examining the influence of intergroup contact." Tourism Management 50: 292-305.

MacCannell, Dean. 1976. The Tourist: A New Theory of the Leisure Class. University of California Press.

Milman, Ady, Arie Reichel, and Abraham Pizam. 1990. "The impact of tourism on ethnic attitudes: the Israeli-Egyptian case." Journal of Travel Research 29(2): 45-49.

Ming Pao. 2013, January 14. "LANEIGE Hong Kong Was Complained to Discriminate Hong Kong Local Residents by Refusing to Sell Them Christmas Packages”, Highlights. 
Mo, Chul-min, Dennis R. Howard, and Mark E. Havitz. 1993. "Testing an international tourist role typology." Annals of Tourism Research 20(2): 319-335.

Nash, Dennison. 1989. “Tourism as a form of imperialism”. In V. L. Smith Hosts and Guests: The Anthropology of Tourism (37-52). Philadelphia: University of Pennsylvania Press.

Ng, Siew Imm, Julie Anne Lee, and Geoffrey N. Soutar. 2007. "Tourists’ intention to visit a country: The impact of cultural distance." Tourism Management 28(6): 1497-1506.

Nuñez, Theron. and J. Lett. 1989. “Touristic studies in anthropological perspective.” In V. L. Smith Hosts and Guests: The Anthropology of Tourism (265-274). Philadelphia: University of Pennsylvania Press.

Pearce, Philip L. 1982. "Tourists and their hosts: Some social and psychological effects of intercultural contact.” In S. Bochner Cultures in Contact: Studies in Cross-Cultural Interaction (p. 199). New York: Pergamon Press Ltd.

Pettigrew, Thomas F. 1998. "Intergroup contact theory." Annual Review of Psychology 49(1): 65-85.

Pizam, Abraham, Jafar Jafari, and Ady Milman. 1991. "Influence of tourism on attitudes: US students visiting USSR." Tourism Management 12(1): 47-54.

Pizam, Abraham, Natan Uriely, and Arie Reichel. 2000. "The intensity of tourist-host social relationship and its effects on satisfaction and change of attitudes: the case of working tourists in Israel." Tourism Management 21(4): 395-406.

Pizam, Abraham. 1996. “Does tourism promote peace and understanding between unfriendly nations?” Tourism, Crime and International Security Issues: 203-213.

Rasmi, Sarah, SiewImm Ng, Julie A. Lee, and Geoff N. Soutar. 2014. "Tourists' strategies: An acculturation approach." Tourism Management 40: 311-320.

Reisinger, Yvette, and Lindsay Turner. 1998a. "Cross-cultural differences in tourism: A strategy for tourism marketers." Journal of Travel \& Tourism Marketing 7(4): 79-106. 
Reisinger, Yvette, and Lindsay Turner. 1998b. "Cultural differences between Mandarin-speaking tourists and Australian hosts and their impact on cross-cultural tourist-host interaction." Journal of Business Research 42(2): 175-187.

Reisinger, Yvette, and Lindsay W. Turner. 2002a. "Cultural differences between Asian tourist markets and Australian hosts, Part 1." Journal of Travel Research 40(3): 295-315.

Reisinger, Yvette, and Lindsay W. Turner. 2002b. "Cultural differences between Asian tourist markets and Australian hosts: Part 2." Journal of Travel Research 40(4): 385-395.

Rothman, Robert A. 1978. "Residents and transients: community reaction to seasonal visitors." Journal of Travel Research 16(3): 8-13.

Schwartz, Lisa K., and Joseph P. Simmons. 2001. "Contact quality and attitudes toward the elderly." Educational Gerontology 27(2): 127-137.

Segall, Marshall H. 1979. Cross-Cultural Psychology: Human Behavior in Global Perspective. Monterey, CA: Brooks/Cole.

Song, Zibin, Lijuan Xing, and Prakash K. Chathoth. 2015. "The effects of festival impacts on support intentions based on residents' ratings of festival performance and satisfaction: a new integrative approach." Journal of Sustainable Tourism 23(2): 316-337.

Spradley, James P., and Mark Phillips. 1972. "Culture and stress: A quantitative analysis." American Anthropologist 74(3): 518-529.

Stephan, Walter G., and Cookie White Stephan. 1985. "Intergroup anxiety." Journal of Social Issues 41(3): 157-175.

Stephan, Walter G., and Krystina Finlay. 1999. "The role of empathy in improving intergroup relations." Journal of Social Issues 55(4): 729-743.

Sutton, Willis A. 1967. “Travel and understanding: Notes on the social structure of touring”. International Journal of Comparative Sociology, 8 (2): 217-223.

Triandis, Harry C. 1994. Culture and Social Behavior. New York: McGraw-Hill. 
Tsai, Jeanne L., Yulia Chentsova-Dutton, and Ying Wong. 2002. "Why and how we should study ethnic identity, acculturation, and cultural orientation.” In G. Hall \& S. Okazaki (Eds.). Asian American Psychology: The Science of Lives in Context (467-491) Washington, DC: American Psychological Association.

Tylor, Edward Burnett. 1924. orig. 1871. Primitive Culture: Researches into the Development of Mythology, Philosophy, Religion, Art, and Custom. London: John Murray Publishers Ltd.

Wei, Lu, John L. Crompton, and Leslie M. Reid. 1989. "Cultural conflicts: Experiences of US visitors to China." Tourism Management 10(4): 322-332.

Wish, Myron. 1976. "Comparisons among multidimensional structures of interpersonal relations." Multivariate Behavioral Research 11(3): 297-324.

Woosnam, Kyle M., and Kayode Dare Aleshinloye. 2012. "Can tourists experience emotional solidarity with residents? Testing Durkheim’s model from a new perspective”. Journal of Travel Research, 52(4): 494-505.

Ye, Ben Haobin, Hanqin Qiu Zhang, and Peter P. Yuen. 2013. "Cultural conflicts or cultural cushion?." Annals of Tourism Research 43: 321-349.

Yu, Jiyun, and Timothy Jeonglyeol Lee. 2014. "Impact of tourists’ intercultural interactions." Journal of Travel Research 53(2): 225-238. 
Table 1. Demographic Profile of Samples ( $\mathrm{n}=496)$

\begin{tabular}{|c|c|c|c|}
\hline Demographics & $\%$ & Demographics & $\%$ \\
\hline Gender & & Marital Status & \\
\hline Male & 54.5 & Single & 34.9 \\
\hline Female & 45.5 & Married with child(ren) & 49.4 \\
\hline Age & & Married without child(ren) & 14.2 \\
\hline $18-24$ & 10.1 & Others & 1.5 \\
\hline $25-34$ & 22.6 & Occupation & \\
\hline $35-44$ & 26.7 & Managers and administrators & 37.3 \\
\hline $45-64$ & 37.0 & Professionals & 29.6 \\
\hline 65 or above & 5.5 & Associate professionals & 2.7 \\
\hline Education & & Clerks & 7.0 \\
\hline Primary or below & 0.8 & Service workers and shop sales workers & 3.3 \\
\hline Secondary school & 14.7 & Craft and related workers & 1.0 \\
\hline Diploma/Certificate & 15.3 & Retired & 4.8 \\
\hline Sub-degree course & 3.1 & Students & 7.5 \\
\hline Bachelor or above & 66.1 & Not applicable & 6.8 \\
\hline \multicolumn{4}{|l|}{ Monthly Personal Income } \\
\hline $0-9,999$ & 0.4 & & \\
\hline 10,000-19,999 & 10.1 & & \\
\hline 20,000-29,999 & 9.0 & & \\
\hline 30,000-39,999 & 13.3 & & \\
\hline $40,000-49,999$ & 7.9 & & \\
\hline 50,000-59,999 & 10.5 & & \\
\hline 60,000 or above & 31.5 & & \\
\hline Not applicable & 17.3 & & \\
\hline
\end{tabular}


Table 2. Results of the Overall Measurement Model $(n=496)$

\begin{tabular}{l} 
Measures \\
\multicolumn{1}{c}{ Cultural Distance } \\
\hline Cultural Retention \\
People in Mainland China and Hong Kong are different in traditional \\
customs. \\
People in Mainland China and Hong Kong are different in richness of \\
traditional customs. \\
People in Mainland China and Hong Kong are different in their sense of \\
cultural retention.
\end{tabular}

Composite
Reliability

0.765

Standardized
Factor
Loading

ding

\section{Behavioral Characteristics}

People in Mainland China and Hong Kong are different in civilization level.

People in Mainland China and Hong Kong are different in hygiene standard.

People in Mainland China and Hong Kong are different in privacy protection.

\section{Social Characteristics}

People in Mainland China and Hong Kong are different in the way of communication.

People in Mainland China and Hong Kong are different in the way of making friends.

\section{Social-Oriented}

\section{Quantity of Contact}

Interaction with the locals when traveling together (showing around)

Interaction with the locals in participating performance

Interaction with the locals by exchanging gifts

Interaction with the locals by experiencing their customs

Interaction with the locals when a conflict exists

Interaction with the locals by enquiring or receiving help from them

Interaction with the locals by visiting their homes

\section{Service-Oriented}

Interaction with the service personnel during dining Interaction with the service personnel in accommodation

Interaction with the service personnel during shopping Interaction with the service personnel in transportation Interaction with the locals during leisure activities
0.740

\subsection{7}

0.702

0.672

0.775

\subsection{4}

0.685

0.663

0.891

0.692

0.890

$\begin{array}{ll}0.818 & * * * \\ 0.791 & * * * \\ 0.775 & * * * \\ 0.718 & * * * \\ 0.694 & * * * \\ 0.669 & * * * \\ 0.646 & * * *\end{array}$

0.868

$\begin{array}{ll}0.807 & * * * \\ 0.784 & * * * \\ 0.749 & * * * \\ 0.718 & * * * \\ 0.711 & * * *\end{array}$




\section{Quality of Contact}

Harmonious

Friendly

Intense

Equal

Cooperative

0.856

$* * * \mathrm{p}<0.001$ 
Table 3. Correlation (Squared Correlation) and Average Variance Extracted (AVE) for the Hypotheses Model

\begin{tabular}{|c|c|c|c|c|c|c|}
\hline & $\begin{array}{l}\text { Cultural } \\
\text { retention }\end{array}$ & $\begin{array}{c}\text { Behavioral } \\
\text { characteristics }\end{array}$ & $\begin{array}{c}\text { Social } \\
\text { characteristics }\end{array}$ & $\begin{array}{c}\begin{array}{c}\text { Social- } \\
\text { oriented } \\
\text { contact }\end{array} \\
\end{array}$ & $\begin{array}{c}\begin{array}{c}\text { Service- } \\
\text { oriented } \\
\text { contact }\end{array} \\
\end{array}$ & Quality \\
\hline Cultural retention & 1 & & & & & \\
\hline Behavioral characteristics & $0.694(0.482)$ & 1 & & & & \\
\hline Social characteristics & $0.556(0.309)$ & $0.628(0.394)$ & 1 & & & \\
\hline Social-oriented contact & $0.062(0.004)$ & $0.016(0.000)$ & $-0.059(0.003)$ & 1 & & \\
\hline Service-oriented contact & $0.126(0.016)$ & $0.098(0.010)$ & $0.017(0.000)$ & $0.700(0.490)$ & 1 & \\
\hline Quality & $-0.052(0.003)$ & $-0.181(0.033)$ & $-0.174(0.030)$ & $0.281(0.079)$ & $0.277(0.077)$ & 1 \\
\hline AVE & 0.521 & 0.487 & 0.636 & 0.537 & 0.570 & 0.550 \\
\hline
\end{tabular}




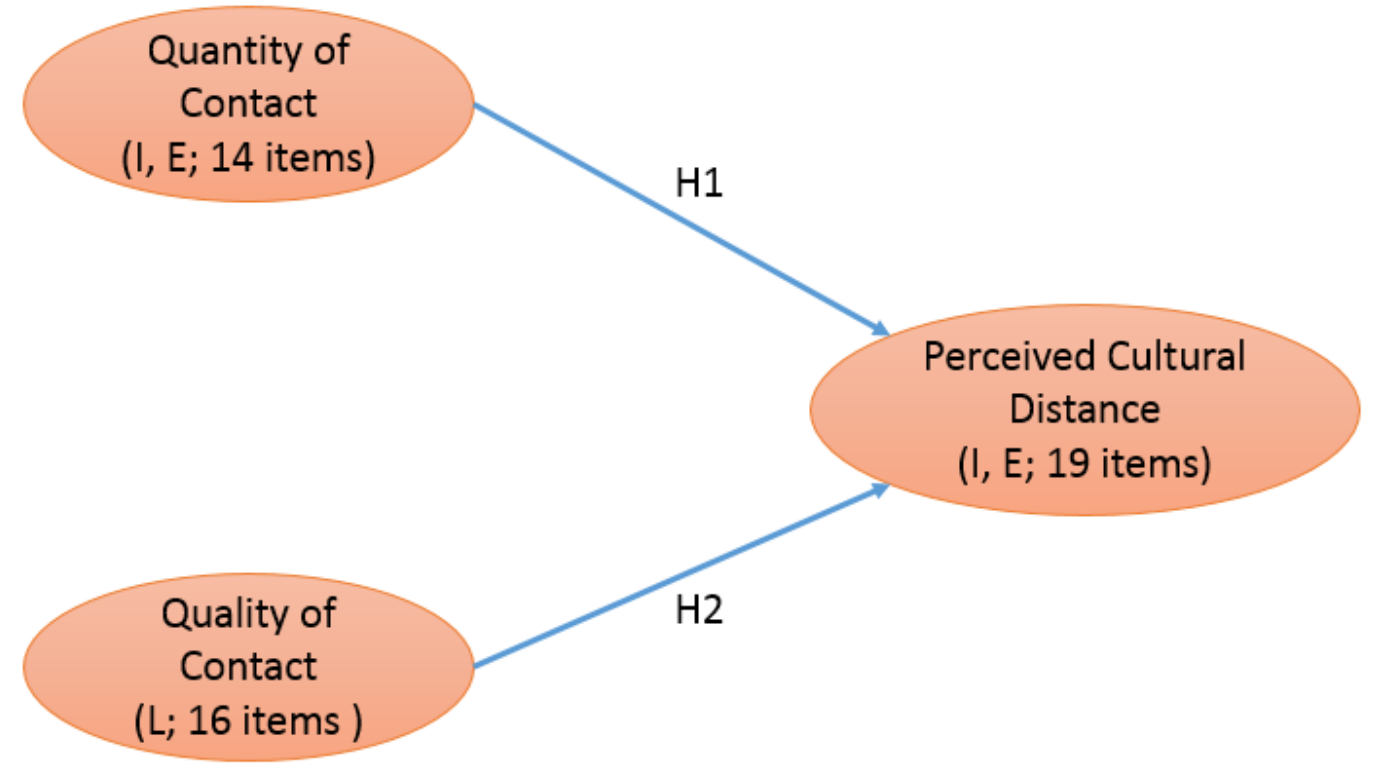

Notes: I-interviews; E-expert panel review; L-literature.

The item numbers refer to those items retained after the interviews and expert panel review, but before the conduct of the survey.

Figure 1. Techniques and Item Numbers for Each Construct in the Conceptual Framework 


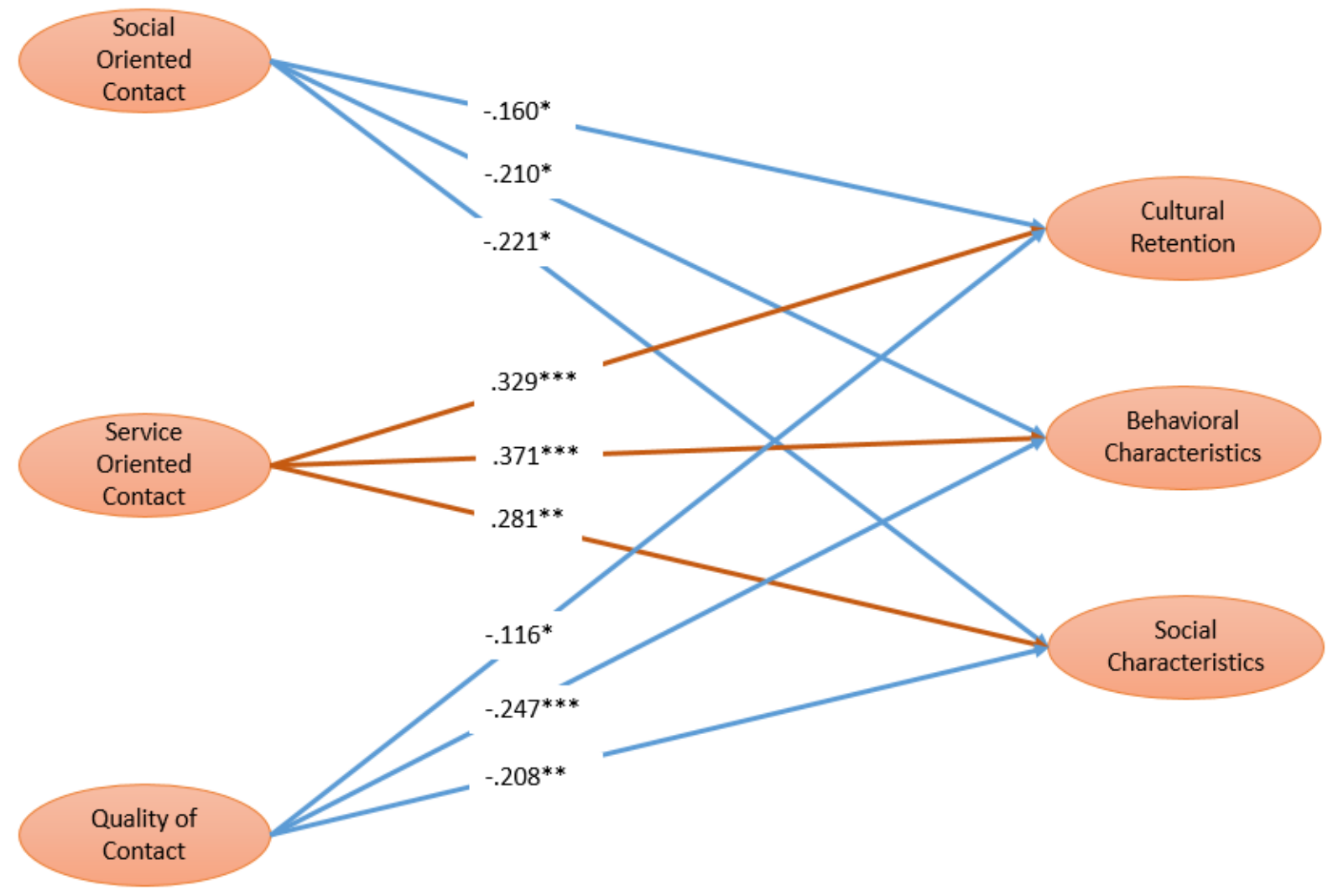

* Significant path at the 0.05 level ** Significant path at the 0.01 level *** Significant path at the 0.001 level

Figure 2. Final Structural Model with Standardized Paths 